\title{
HASIL TANGKAPAN IKAN MADIDIHANG DARI ASPEK TEKNIS DAN BIOLOGI MENGGUNAKAN ARMADA PANCING TONDA DI PERAIRAN PALABUHANRATU
}

\section{ANALYSIS OF TECHNICAL AND BIOLOGICAL YELLOW FIN TUNA WITH TONDA VASSEL CATCH IN PALABUHANRATU}

\author{
Muhammad Ihsan $^{1}$, Roza Yusfiandayani ${ }^{2}$, Mulyono S. Baskoro ${ }^{2}$, Wazir Mawardi ${ }^{2}$ \\ ${ }^{1}$ Program Studi Teknologi Perikanan laut, Sekolah Pascasarjana \\ ${ }^{2}$ Departemen Pemanfaatan Sumberdaya Perikanan, \\ Fakultas Perikanan dan Ilmu Kelautan, Institut Pertanian Bogor \\ Korespondensi :mb114413@gmail.com,ochaipb@gmail.com, baskoro.mul@gmail.com,wmawardi@gmail.com
}

\begin{abstract}
The development of fisheries in the consisting area from various aspects, one of them from the biological aspect. The biological aspect has important effort for fisheries development in the area. Biological aspect for this research is useful to know composition of gastric yellowfin tuna that landed on PPN Palabuhanratu. Sample yellowfin tuna taken on August 2015 to December 2015 from a fisherman in the PPN Palabuhanratu In the operation of tonda fishing vassel, haved 4 types of fishing gear used are taber, tomba, fishing line, and kite which have different type and function of catch. for the measurement of the total-length, total-weight and length-weight correlation analysis. The data have been calculated between correlation from total-length and total-weight of yellowfin tuna were issometric with $\mathrm{b}$ values 3.304. The total length of tuna madidihang obtained in total ranges from $39-68 \mathrm{~cm}$ FL. The long-term frequency distribution of tuna madidihang for five months is dominated by the size $<100 \mathrm{~cm}$ FL. Based on the observation of the fishing fleet of tents, each fishing gear used has different ways of catching operations with different catches. Madidihang in PPN Palabuhanratu and based on the length-weight correlation analysis is issometric results obtained in which the growth of yellow fin tuna weight normal with the growth of length but to much jouvenile to catch with this fisshing vassel, it have lokked at leght distribution analysis $55 \%$ are have juvenile leght.
\end{abstract}

Keyword: technical aspects, biology aspects, tonda fishing, yellowfin tuna

\section{ABSTRAK}

Pembangunan perikanan di daerah terdiri dari berbagai aspek, salah satunya adalah aspek teknis dan aspek biologis. Aspek biologis memiliki peranan penting untuk pengembangan perikanan di suatu daerah. Aspek teknis digunakan untuk melihat bagaimana cara madidihang tertangkap dan aspek biologis digunakan dalam penelitian ini berguna untuk mengetahui perkembangan penangkapan pada objek ikan yang tertangkap dalam hal ini adalah madidihang yang mendarat di PPN Palabuhanratu. Sampel madidihang diambil pada Agustus 2015 sampai Desember 2015 dari seorang nelayan di PPN Palabuhanratu. Pengoperasian armada pancing tonda, digunakan 4 alat jenis alat tangkap yaitu taber, tomba, pancing ulur, dan layang-layang yang mempunyai fungsi dan jenis hasil tangkapan yang berbeda. Pengukuran total panjang total berat dan analisis korelasi panjang-berat. Data yang telah dihitung antara korelasi dari jumlah panjang dan jumlah-berat madidihang yang issometric dengan b nilai 3.304. Panjang tuna madidihang yang didaratkan secara keseluruhan berkisar antara 39-68cm FL. Distribusi frekuensi panjang tuna madidihang selama lima bulan didominasi oleh ukuran $<100 \mathrm{~cm}$ FL. Berdasarkan pengamatan armada pancing tonda, tiap alat tangkap yang digunakan mempunyai cara yang berbeda-beda dalam operasi penangkapannya dengan hasil tangkapan yang berbeda. Berdasarkan analisis korelasi panjang-berat, madidihang memiliki hasil isometrik yang dapat disimpulkan bahwa pertumbuhan madidihang berkembang dengan baik. Hasil tangkapan bedasarkan analisis selang kelas panjang madidihang menunjukan 55\% hasil tangkapan berada pada ukuran jouvenile.

Kata kunci: aspek teknis, aspek biologi, madidihang, pancing tonda 


\section{PENDAHULUAN}

Pemanfaatan sumberdaya perikanan madidihang di Samudera Hindia dilakukan oleh perikanan industri dan perikanan rakyat (artisanal) yang banyak dijumpai di Palabuhanratu. Usaha penangkapan madidihang sudah berkembang sejak tahun 1965 dan pada saat ini telah menjadi mata pencaharian pokok untuk banyak orang termasuk perikanan madidihang skala kecil (Miyake et al. 2004; anonim 2009). Industri penangkapan tuna madidihang, selain dengan alat tangkap longline digunakan juga alat tangkap pancing tonda, yang beroperasi disekitar laut dalam. Kawasan timur Indonesia alat ini berkembang di daerah Sulawesi Utara, teluk Tomini, Laut Maluku dan, Selat Makasar. Saat ini armada perikanan tuna skala kecil yang berkembang adalah perahu motor tempel dengan dimensi kapal 10 GT, tetapi, di beberapa daerah terdapat perikanan rakyat yang menggunakan kapal motor dimensi kapal hingga 25 GT. Alat tangkap yang digunakan perikanan rakyat untuk penangkapan ikan pelagis besar di Indonesia yang beroperasi di Samudera Hindia adalah troll lines, purse seine dan gillnets hanyut (Proctor et al. 2003).

Armada pancing tonda dikenalkan pertama kali oleh nelayan Bugis yang biasa disebut samoboat, samoboat menggunakan perahu motor dengan alat tangkap menggunakan layang-layang. Berkembangnya kapal pancing tonda tidak terlepas dari perkembangan rumpon yang berada diselatan Jawa Barat. Pancing tonda berkembang sejak 10 tahun terakhir namun tercatat mulai tahun 2005, hingga tahun 2009 pancing tonda jumlahnya lebih banyak dari gillnet (Anggawangsa \& Hargiyatno 2012). Pancing tonda di Palabuhan ratu sering juga disebut sebagai pancing tonda. Jumlah unit pancing tonda terus meningkat setiap tahunnya. Peningkatan ini terjadi karena pengoperasian pancing tonda memiliki beberapa keunggulan diantaranya biaya operasi penangkapan relatif kecil, kualitas ikan hasil tangkapan merupakan komoditas ekspor, operasi penangkapan tidak tergantung pada musim ikan, daerah penangkapan sudah pasti pada rumpon yang dipasang dan produktivitas penangkapan yang tinggi (Wudianto et al. 2003). Keunggulan-keunggulan pengoperasian pancing tonda dikarenakan dalam satu armada penangkapan dioperasikan empat alat tangkap sekaligus. Pengoperasian keempat alat tangkap tersebut tergantung dari cuaca dan lokasi penangkapan, Pengembangan keempat alat tangkap yang di kategorikan pancing tonda di perairan Pelabuhanratu perlu dikaji untuk menentukan keberlanjutan pancing tonda di rumpon.

Ikan madidihang atau dalam nama internasional yang dikenal dengan yellowfin tuna (YFT) yang didaratkan di Palabuhanratu adalah jenis ikan pelagis besar, yang diketahui sebagai perenang cepat, selalu berkelompok dalam pergerakannya dan penyebarannya yang hampir berada di seluruh wilayah pengelolaan perikanan Indonesia memiliki nilai produksi tertinggi kedua setelah cakalang dari tahun 2002 sampai 2014. Ikan ini termasuk dalam genus Thunnus, Thunnini, subfamili Scombrinae, famili Scombridae dan memiliki nama ilmiah Thunnus albacaresBonnaterre, 1788 (Collette \& Nauen 1983) dan merupakan salah satu sumberdaya ikan yang memiliki nilai ekonomis tinggi karena sudah sulit untuk ditangkap oleh nelayan di Palabuhanratu, tetapi permintaannya yang terus meningkat dan telah mendorong upaya penangkapan yang semakin intensif. Tingkah laku ikan pada suatu ekosistem erat kaitannya dengan kegiatan penangkapan (Baskoro \& Taurusman 2011), dimana dalam hal ini madidihang memiliki tekanan penangkapan yang relatif tinggi dalam kurun waktu beberapa tahun akhir. Selama ini penelitian tingkah laku ikan terhadap alat tangkap telah banyak dilakukan. Salah satu pendekatan untuk mengetahui dampak penangkapan terhadap ekosistem adalah mengevaluasi perubahan struktur jaring makanan pada suatu ekosistem sebagai akibat kegiatan penangkapan. Kebiasaan makan, dan posisi tingkat trofik jenis ikan tersebut dalam ekosistem diperlukan (Martin \& Bateson 2010). Hal ini merupakan salah satu kajian yang penting dalam penerapan pengelolaan perikanan dengan pendekatan ekosistem (Ecosystem Approach to Fisheries Management) dalam mewujudkan pengelolaan perikanan yang berkelanjutan. Tujuan penelitian ini adalah Menganalisis aspek teknis alat tangkap madidihang di perairan Palabuhanratu dan menganalisis aspek biologi yang meliputi panjang berat dan distribusi frekuensi panjang ikan madidihang yang tertangkap oleh armada tonda di Palabuhanratu. 


\section{METODE PENELITIAN}

Penelitian diawali dengan pra survei pada bulan Agustus 2014 dan dilanjutkan dengan pengambilan data lapangan yang dilakukan pada bulan Agustus-Desember 2015 di perairan Palabuhanratu (Gambar 1).

Bahan dan alat yang digunakan dalam penelitian ini adalah alat tangkap armada pancing tonda, ikan tuna sirip kuning (Thunnus albacares) atau yang biasa disebut dengan madidihang yang diperoleh dari hasil tangkapan langsung di perairan
Palabuhanratu, timbangan, meteran gulung, GPS, kamera. Metode pengambilan data meliputi data primer dan data sekunder. Data primer dilakukukan dengan metode observasi mengikuti uji coba penangkapan selama bulan Agustus-Desember 2015. Data yang diambil adalah data panjang dan berat ikan. Data sekunder di dapat dengan cara wawancara dan pengambilan data statistik dari Dinas Kelautan dan Perikanan kab. Palabuhanratu. Data yang diambil adalah data biologi berupa panjang, berat, dan isi lambung.

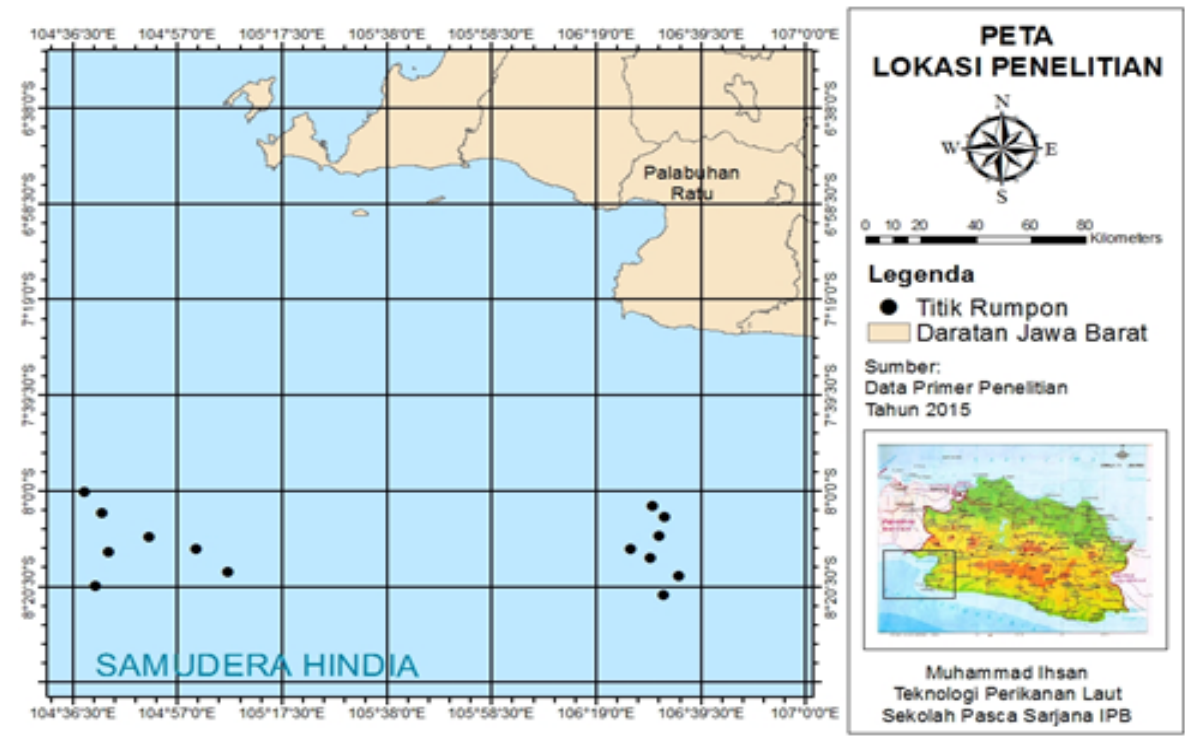

Gambar 1. Peta daerah penangkapan di perairan Palabuhanratu

\section{Analisis data}

\section{Analisis panjang berat}

Analisis hubungan panjang berat ikan menggunakan rumus sebagai berikut (Effendi 1997) :

$$
W i=q \cdot L i^{b}
$$

Wi adalah berat ikan ke i $(\mathrm{kg})$, Li adalah panjang cagak ikan ke i $(\mathrm{cm}), q$ dan $b$ adalah koefisien pertumbuhan berat.

Hubungan panjang berat dapat dilihat dari nilai konstanta $b$ sebagai penduga tingkat kedekatan hubungan kedua parameter melalui hipotesis (Ricker 1975) :

1. Bila $b=3$, memiliki hubungan isometrik (pola pertumbuhan berat sebanding dengan pola pertumbuhan panjang.

2. Bila $\mathrm{b} \neq 3$, memiliki hubungan allometrik (pola pertumbuhan berat tidak sebanding dengan pola pertumbuhan panjang), memiliki dua jenis :

- Bila $\mathrm{b}>3$, mengindikasikan bahwa pertumbuhan berat lebih dominan dibandingkan dengan pertumbuhan panjang.

- Bila $\mathrm{b}<3$, mengindikasikan bahwa pertumbuhan panjang lebih dominan dibandingkan dengan pertumbuhan berat.

\section{Distribusi frekuensi panjang}

Data yang digunakan dalam analisis ini adalah data panjang dan berat tuna madidihang yang didaratkan di PPN Palabuhanratu selama lima bulan AgustusDesember 2015. Data sekunder diperoleh dari pengukuran panjang dan berat ikan dengan kru kapal KM Kresna.

Distribusi frekuensi panjang dan berat tuna madidihang yang didaratkan di PPN Palabuhanratu menggunakan metode Sturges dalam Sudjana (1996): 
- Tentukan rentang kelas, dengan cara nilai maximum dikurangi nilai minimum.

- Tentukan banyak kelas interval yang diperlukan. Banyak kelas interval biasa digunakan paling sedikit 5 dan paling banyak 15 kelas, pilihlah berdasarkan keperluan. Ada cara lain untuk jumlah data $\geq 200$, misalnya dengan aturan Sturges yaitu:

$$
\text { Banyak kelas }=1+(3.3) \log n
$$

- Tentukan panjang kelas interval dengan cara:

$$
\text { Panjang kelas interval }=\frac{\text { Rentang kelas }}{\text { Banyak kelas }}
$$

- Tentukan jumlah data pada masingmasing kelas interval, ditambah dengan metode distribusi normal sparre \& Venema (1998:24):

$$
F c(x)=\left(\frac{n d L}{s \sqrt{2 \pi}}\right)\left(\exp \left[-\frac{(x-\bar{x})^{2}}{2 s^{2}}\right]\right)
$$

dimana $F C=$ frekuensi terhitung atau frekuensi teoritis, $n=$ jumlah data, $d L=$ ukuran interval, $s=$ standar deviasi, $\bar{x}=$ nilai rata-rata panjang ataupun berat dan $\pi$ $=3.14159$.

\section{HASIL DAN PEMBAHASAN}

\section{Unit armada pancing tonda}

Kapal

Jenis kapal yang menangkap tuna madidihang di perairan Palabuhanratu adalah jenis kapal Sulawesi atau kapal Mandar. Kapal di Palabuhanratu memiliki ciri-ciri yaitu panjang kapal 10-15 m, lebar kapal 2-3 m, tinggi kapal 3-4 $\mathrm{m}$ atau dengan kata lain bahwa ukuran kapal Mandar tidak lebih dari 15 GT. Jumlah kapal pancing yang terdaftar di PPN Palabuhanratu berjumlah 80 kapal berdasarkan data dari PPN Palabuhanratu. kapal yang digunakan dalam penelitian ini adalah milik masyarakat Palabuhanratu bernama KM KRESNA 1. Jumlah keseluruhan kapal yang dimiliki pemilik adalah 5 buah kapal dengan spesifikasi kapal dan mesin yang sama.

\section{Alat tangkap}

Alat tangkap yang digunakan oleh nelayan pancing tonda di Palabuhanratu banyak ragamnya sesuai dengan kebutuhan dan fungsi dari alat tangkap tersebut. Dalam pengoperasian alat tangkap tersebut memiliki kriteria yang berbeda beda dalam pengoperasiannya.

1. Taber

Pancing taber menggunakan umpan tiruan yang jumlah mata pancingnya lebih dari 9 mata pancing. Jenis pancing tersebut memiliki panjang tali utama antara 15-25 m. Tali utama terbuat dari bahan nilon. Nomor mata pancing yang digunakan adalah ukuran 6-8. Taber merupakan alat tangkap yang pertama kali digunakan operasi penangkapan yang berfungsi sebagai alat tangkap pencari ikan umpan. Taber digunakan mulai pukul 5.00 pagi sampai pukul 6.30 yaitu pada saat kumpulan ikan kecil naik ke permukaan untuk mencari makan. Penggunaan pancing taber yaitu dengan cara di tonda ataupun di coping. Ikan yang dihasilkan dari alat tangkap taber digunakan untuk umpan pada alat tangkap tomba, umpan yang digunakan adalah umpan yang memiliki berat dibawah $1 \mathrm{~kg}$.

\section{Tomba}

Tomba atau dirft lines adalah alat tangkap pancing yang menggunakan umpan hidup yang berasal dari alat tangkap taber, lalu dioperasikan dengan cara di hanyutkan di perairan dengan melihat arah arus dimana tempat ikan berkumpul. Alat tangkap tersebut mempunyai target tangkapan ikan yang berukuran besar karena memiliki mata pancing ukuran No. 1 yang hanya bisa memancing ikan dengan ukuran lebih dari $30 \mathrm{~kg}$. Alat tangkap tomba memiliki spesifikasi yaitu Jerigen 20 liter sebagai pelampung, Senar PA monofilamen no.3000 dengan panjang $45 \mathrm{~m}$, Kili-kili (swivel), Senar PA monofilamen no.1200 dengan panjang $10 \mathrm{~m}$, dan mata pancing no 1 .

\section{Pancing Ulur}

Pancing ulur adalah salah satu alat tangkap yang paling umum dikenal oleh masyarakat, terutama di kalangan nelayan. Pada prinsipnya, pancing terdiri dari dua komponen utama yaitu tali (line) dan mata pancing (hook). Alat tangkap pancing ulur dioperasikan oleh setiap nelayan yang berada dikapal, satu alat tangkap dipegang satu orang. Alat tersebut mempunyai spesifikasi alat tangkap dengan mata pancing ukuran 6-7.

Berdasarkan konstruksinya, pancing ulur 
termasuk dalam kelompok angling (Ayodhyoa 1981). Brandt (2005) mendeskripsikan pancing adalah alat tangkap yang sederhana, dioperasikan oleh nelayan kecil, memerlukan modal kecil dan tidak membutuhkan kapal yang khusus. Alat tangkap pancing ulur digolongkan ke dalam fishing with line yang dilengkapi dengan mata pancing no 6-7, tali utama yaitu senar no. 50-60 dengan panjang 30-50 m, kilikili (swivel), tali cabang dengan senar no.35 sebanyak 12-15 buah yang mempunyai panjang $20-30 \mathrm{~cm}$ serta jarak antar pancing $1 \mathrm{~m}$ dan Pemberat $\pm 1000 \mathrm{~g}$.

Konstruksi pancing ulur di setiap daerah adalah sama. Perbedaannya hanya pada ukuran tali, pancing dan pemberat yang digunakan. Nomura (1981) menyebutkan bahwa pancing ulur tergolong alat tangkap yang sangat sederhana. Hal ini dikarenakan pancing tonda hanya terdiri dari mata pancing, tali, gulungan dan pemberat. Adapun ukuran mata pancing dan besarnya tali yang digunakan disesuaikan dengan ukuran ikan yang menjadi sasaran penangkapan (Farid et al. 1989).

Perikanan pancing ulur adalah sistem penangkapan yang mempergunakan mata pancing dengan atau tanpa umpan yang diikatkan pada tali pancing dan secara langsung dioperasikan dengan tangan manusia. Ciri khas dari penangkapan ini adalah konstruksinya yang sangat sederhana, skalanya kecil dan tidak memerlukan modal yang besar. Jadi, meskipun hasil tangkapannya sedikit, keuntungan masih dapat diandalkan. Selain itu, alat tangkap pancing ulur dapat dioperasikan pada tempat-tempat dimana alat tangkap lain sukar untuk dioperasikan, misalnya di tempat-tempat dalam, berarus cepat atau dasar perairan berkarang (Monintja \& Martasuganda 1991 vide Zainuddin 2002).

\section{Layang-layang}

Alat tangkap layang-layang merupakan alat tangkap yang menggunakan alat bantu layangan dalam pengoprasiannya, alat tangkap tersebut memiliki dua jenis, yaitu layangan yang menggunakan satu umpan dan kondo-kondo yang mempunyai tiga umpan. Bagian utama alat tangkap layanglayang yaitu Tali utama dengan jenis Senar no.60-80 yang mempunyai panjang 30-60 $\mathrm{m}$, Kili-kili (swivel) Tali pancing dengan jenis bahan Senar no.50-60 mempunyai panjang 3-3.5 m serta jarak antar tali pancing 7-10 $\mathrm{m}$, mata pancing no5-7, layang-layang bahan plastik, kerangka bambu.

Alat tangkap layangan yang menggunakan satu umpan mempunyai ukuran umpan yang besar disesuaikan dengan ukuran mata kail yang digunakan. Alat tangkap layangan dengan satu umpan mempunyai tiga mata kail dengan ukuran yang besar Hasil tangkapan utama adalah tuna ukuran besar dengan bobot lebih dari $30 \mathrm{~kg}$.

Salah satu alat tangkap yang menggunakan layangan adalah kondokondo, alat tangkap tersebut mempunyai 3 umpan dengan ukuran mata kail lebih kecil dari pada layangan. Hasil tangkapan alat tangkap tersebut mempunyaui ukuran yang lebih kecil dan mendapatkan hasil tangkapan yang lebih banyak. Dalam pengoperasian alat tangkap keduanya mempunyai proses yang sama, namun perbedaan kedua alat tangkap yaitu berupa ukuran dan jenis hasil tangkapan.

\section{Hubungan panjang berat}

Hubungan panjang berat ikan merupakan pengetahuan yang wajib diketahui dalam bidang biologi perikanan yang ditujukan untuk kepentingan pengelolaan perikanan. Menurut Merta (1993) menyatakan bahwa hubungan panjang berat dimaksudkan untuk mengukur variasi berat harapan untuk panjang tertentu dari ikan secara individual atau kelompok individu sebagai suatu petunjuk tentang kegemukan, kesehatan, perkembangan gonad dan sebagainya. Penelitian ini hubungan panjang berat hanya digunakan untuk melihat pola berat tuna madidihang berdasarkan waktu, karena Effendi (1997) menyatakan bahwa berat ikan dapat dianggap sebagai suatu fungsi dari panjangnya dan hubungan panjang berat hampir mengikuti hukum kubik. Hubungan panjang berat ikan pada bab ini hanya ditujukan untuk tuna madidihang (Gambar 2).

Nilai b biasanya berkisar antara 2.5 sampai 4.0 (Hile 1936; Martin 1949). Allen (1938) telah melakukan penelitian bahwa bentuk tubuh ikan yang ideal memiliki nilai $\mathrm{b}=3$. Beverton dan Holt (1957) melaporkan bahwa hukum kubik dari hubungan panjang berat memiliki nilai yang hampir mendekati 3. Carlander (1969) menyatakan bahwa berat ikan meningkat secara logaritma seiring dengan peningkatan panjangnya yang memiliki nilai berkisar 2.5 sampai 3.5 tetapi biasanya sangat 
mendekati 3.0. Ricker (1975) melihat nilai b sebagai penggambaran pertumbuhan, jika $\mathrm{b}=3$ menggambarkan pertumbuhan yang isometrik, dan jika b lebih besar atau kurang dari 3 menggambarkan pertumbuhan yang alometrik. Penelitian ini menghasilkan nilai berkisar antara 3.032. Hal tersebut menunjukan bahwa tuna madidihang yang didaratkan di PPN Palabuhanratu memiliki ukuran pertumbuhan yang sangat mendekati 3.0 dan ideal, begitu juga dengan nilai $\mathrm{b}$ gabungan data dari 5 bulan tersebut.

\section{Distribusi frekuensi panjang}

Distribusi frekuensi panjang tuna madidihang yang didaratkan di PPN Palabuhanratu periode bulanan selama 5 bulan disajikan pada Gambar 3. Panjang tuna madidihang yang didaratkan secara keseluruhan berkisar antara 39-68 cm FL. Distribusi frekuensi panjang tuna madidihang selama lima bulan didominasi oleh ukuran $<100 \mathrm{~cm}$ FL.

Distribusi frekuensi panjang tuna madidihang yang didaratkan di PPN Palabuhanratu periode bulanan selama 5 bulan terakhir agustus-desember disajikan pada Gambar 6. Berat tuna madidihang yang didaratkan secara keseluruhan berkisar antara 10-96 kg. Distribusi frekuensi berat tuna madidihang selama 5 bulan didominasi $(87.43 \%)$ oleh ukuran $\leq 100 \mathrm{~kg}$ dan sisanya berada pada ukuran $\geq 100 \mathrm{~kg}$.

Dominansi ukuran tuna madidihang $\leq 100 \mathrm{cmFL}$ yang didaratkan di PPN Palabuhanratu dapat dikatakan penangkapan yang tidak berkelanjutan, dikarenakan beberapa peneliti menyatakan bahwa ukuran panjang dan berat tuna madidihang pada saat pertama kali matang gonad adalah $\geq 100 \mathrm{cmFL}$ dan $\geq 20 \mathrm{~kg}$ (Nootmorn et al. 2005; Kantun et al. 2011; Zhu et al. 2008 dalam Wujdi et al. 2014). Madidihang ukuran kecil banyak tertangkap dan tidak dilaporkan, karena tuna ukuran kecil digunakan sebagai umpan untuk menangkap madidihang yang berkuruan $\geq 100 \mathrm{~cm}$ dan banyak digunakan sebagai bahan dasar untuk makanan kaleng serta diolah menjadi makanan ternak. Hal tersebut menunjukan bahwa peran permintaan dari pasar dan industri akan membuat nelayan tidak selektif terhadap ukuran.

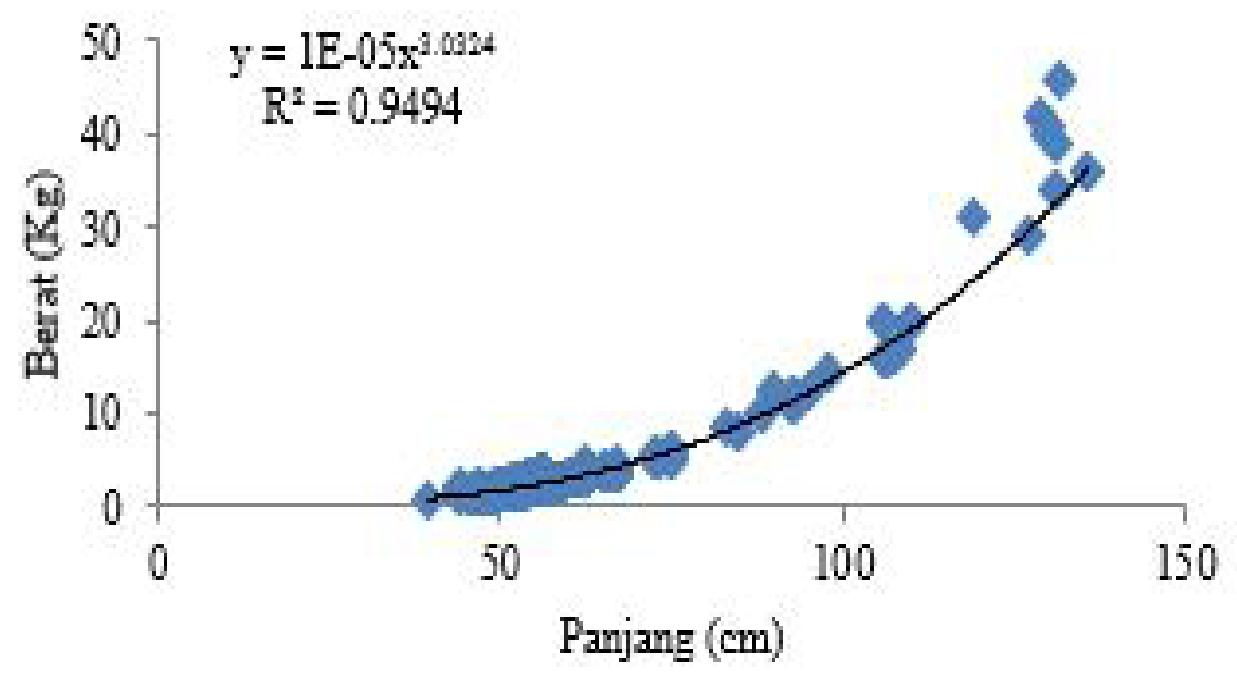

Gambar 2. Hubungan panjang berat madidihang 

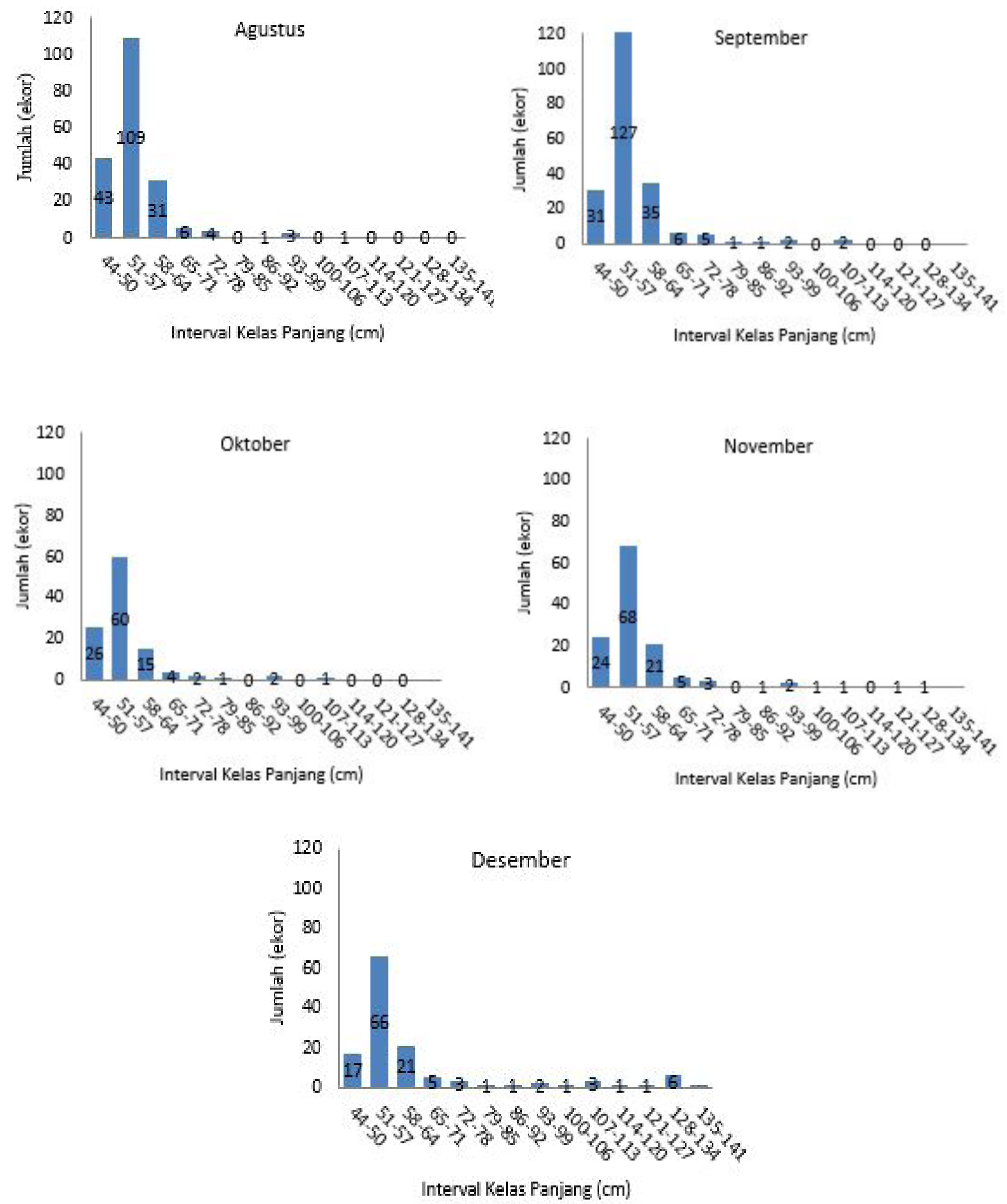

Gambar 3. Distribusi frekuensi panjang madidihang 


\section{KESIMPULAN DAN SARAN}

\section{Kesimpulan}

Armada pancing tonda di Palabuhanratu memiliki 4 macam alat tangkap yang dalam pengoperasiannya berbeda teknik penangkapannya. Setiap alat tangkap memiliki fungsi yang berbeda-beda sesuai dengan besarnya hasil tangkapan, dalam penelitian ini pancing ulur memiliki performance paling baik dalam menangkap madidihang. Panjang tuna madidihang selama penelitian memiliki nilai $\mathrm{b}=3.032$ yang menunjukkan nilai isometrik dan dominansi ukuran panjang madidihang s $100 \mathrm{~cm}$ sebanyak 87.43\% dengan ukuran antara $44-85 \mathrm{~cm}$.

\section{Saran}

Diperlukan kajian lanjutan mengenai komponen dan struktur alat tangkap di ekosistem perairan samudra hindia khususnya di perairan Palabuhanratu agar diperoleh informasi ilmiah sebagai dasar pengelolaan perikanan yang lebih baik. Perlu adanya perbaikan alat tangkap mengingat hasil tangkapan yang tertangkap masih belum layak tangkap.

\section{DAFTAR PUSTAKA}

Ayotte L. 2005. Sharks-Educator's Guide. 3D Enterteaintment 1td. And United Nation Evironment Program.

Baskoro MS, Taurusman AA. 2011. Tingkah Laku Ikan : Hubungannya dengan Ilmu dan Teknologi Perikanan Tangkap. Bandung (ID) : CV Lubuk Agung.

Cury P, Shannon L, Shin YJ. 2003. The Function of Marine Ecosystems : a Fisheries Perspective. Sinclair M, Valdimarsson G, editor. Wallingford (UK) : CABI Publishing.

Direktorat Jenderal Perikanan Tangkap. 2013. Laporan Akuntabilitas Kinerja Instansi Pemerintah (LAKIP) Direktorat Jenderal Perikanan Tangkap Tahun 2012. Jakarta : Kementerian Kelautan dan Perikanan.

Bonfil R, Amorim A, Anderson C, Arauz $\mathrm{R}$, Baum J, Clarke SC, Graham R T, Gonzalez M, Jolón M, Kyne PM, Mancini P, Márquez F, Ruíz C, Smith W. 2009. Carcharhinus falciformis. The IUCN Red List of Threatened Species. Version 2014.2 [Internet]. [diunduh 2014 Nov 5]. Tersedia pada: www.iucnredlist.org.

Efendie, MI. 1972. Metoda Biologi Perikanan. Bogor (ID) : Yayasan Sri Dewi.

Elliot M, et al.2002. Fishes in Estuaries. editor M.Eliott and K.L. Hemingway. United Kingdom : Blackwell.

Fahmi, Dharmadi. 2013. Tinjauan Status Perikanan Madidihang dan Upaya Konservasinya di Indonesia. Direktorat Konservasi Kawasan dan Jenis Ikan. Jakarta (ID): Kementrian Kelautan dan Perikanan Republik Indonesia.

Illahude A . 1978. On The Effecting The Productivity of The Southern Makassar Strait. Marine Research in Indonesia. 21: 81-107.

Jaenuddin A. 2013. Kebiasaan Makan Ikan Tuna (Thunnus sp.) terkait dengan Proses Penangkapan pada Rawai Tuna di Samudera Hindia [skripsi].Bogor (ID) : Institut Pertanian Bogor.

Joice, WN , Campana SE, Natanson LJ, Kohler NE, Pratt Jr HL, Jensen CF. 2002. Analysis of Stomach Content of Porbeagle Shark (Lamna nasus Bonnaterre) in the Northwest Atlantic. ICES Journal of Marine Science. 59 : 1263-1269.

Matthew S. 2003. Small Scale Fisheries Perspective on an Ecosystem-based Approach to Fisheries Management. Sinclair M, Valdimarsson G, editor. Wallingford (UK) : CABI Publishing.

Martin P, Bateson P. 2010. Measuring Behaviour. London (UK) : Cambridge University Press.

Natarajan AV, Jhingran AG. 1961. Index of Preponderance, A Method of Grading the Food Elements in the Stomach of Fishes. Indian J.Fish., 8 (1) : 54-59.

Nazir M. 2003. Metode Penelitian. Jakarta (ID) : Ghalia Indonesia.

Nikolsky G V. 1963. The Ecology of Fishes. Newbury (GB) : Academic Press.

Priyono B, Yunanto A, Arief T. 2008. Karakteristik Oseanografi Dalam Kaitannya Dengan Kesuburan Perairan di Selat Bali. Jembrana (ID): Balai Riset dan Observasi Kelautan.

Sinclair M, Valdimarsson G. 2003. Responsible Fisheries in the Marine Ecosystem. Sinclair M, Valdimarsson $\mathrm{G}$, editor. Wallingford (UK) : CABI Publishing.

Stevens JD, Bofil R, Dulvy NK, Walkers PA. 2000. The Effect of Fishing on Sharks, Rays, and Chimaeras (Chondrichtyans), and the Implication for Marine Ecosystem. ICES Journal of 
Marine Science. 57 : 276-494.

Stergiou KI, Moutopoulus DK, Casal HJA, Erzini K. 2007. Trophic Signatures of Small-Scale Fishing Gears: Implications for Conservation and Management. Marine Ecology Progress Series. No. 333: 117 - 128 .

Stergiou KI, Kapourzi VS. 2002. Feeding Habits and Trophic Levels of Mediterranean Fish. Amsterdam (ND):
Kluwer Academic Publisher.

Torres-Rojas YE, Osuna FP, Herrera AH, Magana FG, Garcia SA, Ortiz HV, Sampson L. 2013. Feeding Grounds of Juvenile Scalloped Hammerhead Sharks (Sphyrna lewini) in the South-Eastern Gulf of California. Hydribiologia Springer Science. DOI: 10.1007/s10750-013-1753-9. 